\title{
Re-etnización y descolonización: resistencias epistémicas en el curriculum intercultural en la Región de Los Lagos-Chile
}

\author{
Pedro Fuenzalida Rodríguez \\ Depto. de Educación, Universidad de Los Lagos, Osorno, Chile \\ Email:pfuenzal@ulagos.cl
}

\begin{abstract}
Resumen: ${ }^{1} \mathrm{La}$ emergencia de la educación intercultural bilingüe en las comunidades mapuche-williche del sur de Chile está implicando, entre otros procesos de significación socio-política, la activación de la memoria colectiva e histórica, permitiendo incorporar, en los flujos de interacción simbólica entre la comunidad y la escuela, dinámicas de legitimación de su cultura y proyectos societales. Estas dinámicas, sin embargo, se ven tensionadas por las concepciones de interculturalidad que promueve el Estado a través de la escuela y las perspectivas que las comunidades construyen desde los liderazgos sociopolíticos. En el marco de estas tensiones, el artículo explora los modos en que la construcción del curriculum intercultural revela asimetrías que, al interior de los dispositivos pedagógicos de legitimación, existen entre los epistemes mapuche y el moderno-occidental-escolar. Así también, se pone énfasis en la activación de la memoria y el conflicto entre racionalidades que han conducido, aún de manera disgregada, a las comunidades a iniciar procesos reetnizadores y plantearse proyectos político-educativos propios.
\end{abstract}

Palabras clave: Re-etnización, descolonización, resistencias epistémicas, curriculum de la interculturalidad.

\section{Re-ethnicity and decolonization: epistemic resistances in the intercultural curriculum in the Los Lagos region, Chile}

\begin{abstract}
The emergence of intercultural bilingual education in MapucheWilliche communities of southern Chile is implying, among other processes of socio-political significance, activation of the collective and historical memory, allowing to incorporate flows of symbolic interaction between the community and school, legitimation dynamics of their culture and societal projects. These dynamics, however, are stressed by the conceptions of multiculturalism that promotes the state through school and the perspectives that the communities built from sociopolitical leaderships. In the context of these tensions, the article explores the ways in which the construction of intercultural curriculum reveals asymmetries that, within pedagogical legitimation devices exist between the Mapuche and the modern-western-school epistemes. Also, emphasis is placed on the activation of the memory and the conflict of rationalities that have conducted communities, still in a disaggregated way, to start a re-ethnicity process and consider their own political-educational projects.
\end{abstract} curriculum.

Key words: Re-ethnicity, decolonization, epistemic resistances, intercultural 
Re-etnicização e descolonização: resistências epistêmicas no currículo intercultural na região de Los Lagos, Chile

Resumo: O surgimento da educação intercultural bilíngue em comunidades Mapuche-Williche no sul do Chile está implicando, entre outros processos de significação sócio-política, a ativação da memória coletiva e histórica, permitindo incorporar nos fluxos de interação simbólica entre a comunidade e a escola, dinâmicas da legitimação de sua cultura e projetos sociais. Essas dinâmicas, no entanto, vêmse tensionadas pelos conceitos de interculturalidade que promove o Estado através da escola e as perspectivas que as comunidades constroem desde liderança social e política. No contexto dessas tensões, o artigo explora as maneiras pelas quais a construção do currículo intercultural revela assimetrias que, dentro dos dispositivos pedagógicos de legitimação, existem entre a episteme Mapuche e a modernaocidental-escolar. Além disso, se coloca ênfase na ativação da memória e do conflito entre racionalidades que têm sido conduzidas, ainda em forma desarticulada, às comunidades a reiniciar processos re-etnizadores e considerar projetos políticoeducacionais próprios.

Palavras-chave: Re-etnicização, descolonização, resistência epistêmica, currículo intercultural.

$* * *$

\section{Introducción}

Hasta finales de los 1980, la inclusión de la diversidad cultural en Chile no constituía una preocupación central de las políticas públicas en educación que se enfocaban al logro de la cobertura plena y la chilenización de las poblaciones indígenas ${ }^{2}$. Simultáneamente, el movimiento socio-político indígena proponía sin embargo la implementación de un modelo educativo que enfatizara en los aspectos interculturales y bilingüísticos. En respuesta, desde comienzos de los 1990, el Estado ha venido formulando una política educativa fundamentada en el concepto de Educación Intercultural Bilingüe -en adelante EIB-, concebida como una acción compensatoria destinada a satisfacer una demanda específica de los pueblos indígenas ${ }^{3}$. En las últimas dos décadas, el despliegue operacional de esta política se ha expresado según dos modalidades: la primera y la más antigua corresponde a la implementación de proyectos pilotos propios de las escuelas ${ }^{4}$ mientras la más reciente refiere a la operacionalización, a partir de 2010, del Decreto Supremo de Educación $\mathrm{N}^{\circ} 280$ de 2009, como Sector de Aprendizaje de Lengua Indígena de $1^{\circ}$ a $8^{\circ}$ año de Enseñanza Básica ${ }^{5}$.

En la Región de Los Lagos, la puesta en marcha de la EIB se inicia, aproximadamente, en el año 1993 con la instalación de los Jardines Infantiles Étnicos concebidos e implementados por la Junta Nacional de Jardines Infantiles (JUNJI) ${ }^{6}$. Entre los años 1995 y 1996, se desarrollan las primeras experiencias de EIB en comunidades mapuche-williche ${ }^{7}$ que contaron con financiamiento de la Corporación Nacional de Desarrollo Indígena (CONADI) y del Ministerio de Educación (MINEDUC) ${ }^{8}$. Posteriormente, en el marco del Programa Orígenes ${ }^{9} y$ de las acciones del Programa de Educación Intercultural Bilingüe (PEIB) del MINEDUC, el proceso fue abarcando un 
número mayor de escuelas, además de extenderse hacia zonas urbanas.

Actualmente, la política pública en EIB se ha materializado a través de un conjunto de normas de diferente jerarquía jurídica. Mientras algunas de ellas son de carácter internacional, como el Convenio N¹69 de la Organización Internacional del Trabajo (OIT), otras aparecen enunciadas en leyes generales -Ley N²0.370 de 2009-y específicas -Ley N¹9.253 de 1993, en decretos -Decreto $\mathrm{N}^{\circ} 280$ de 2009-, en programas temporales como el Programa Orígenes, en experiencias pilotos como los proyectos de EIB financiados por el MINEDUC y la CONADI y, más recientemente, en planes y programas de lengua indígena en el currículum escolar-Decretos $\mathrm{N}^{\circ} 1619$ de 2010, N741 de 2011, N¹479 de 2012 y N²960 de 2012.

Los propósitos políticos y pedagógicos que subyacen en estas experiencias apuntan al mejoramiento de los aprendizajes y la integración de niños, niñas y jóvenes indígenas en la sociedad chilena. En el caso de los jardines infantiles étnicos, la acción institucional se enfoca en la pertinencia cultural, la etnicidad, el rescate y la valoración de la cultura, y el desarrollo de la autoestima del niño indígena. Para las experiencias escolares interculturales, la Ley Indígena prescribe a través de su Artículo $32^{\circ}$ el desarrollo de la EIB como un dispositivo que asegure la formación de los educandos indígenas para su desenvolvimiento en ambas sociedades. Por su parte, el MINEDUC busca:

[...] a) mejorar la calidad de la educación, mediante la contextualización de los planes y programas de estudios a las particularidades culturales de los pueblos indígenas; b) fortalecer el bilingüismo como oportunidad de desarrollo cognitivo y de refuerzo cultural lingüístico; c) favorecer la participación de las comunidades en el proceso de formación de los niños y niñas que asisten a los establecimientos focalizados del programa, fortaleciendo estrategias de vinculación con los docentes y directivos, para trabajar en conjunto a la incorporación del conocimiento indígena al currículo, gestión pedagógica, metodologías y evaluación (MINEDUC 2009: 11)

Sin embargo, mis propias experiencias en comunidades mapuchewilliche, me han permitido constatar las distancias ideológicas que los líderes y dirigentes comunitarios mantienen en sus discursos educativos con los propósitos institucionales de la política intercultural del Estado. Los discursos de reclamo, demandas y propuestas educativas de un importante segmento de la sociedad mapuche-williche explicitan intencionalidades que conciben a la escuela como un importante espacio socio-político desde el cual es posible construir proyectos societales propios que rompen con las actuales lógicas que fundan y dan forma a las relaciones de poder actuales.

La concepción e implementación de la EIB ha implicado la intervención en diferentes niveles e instancias del campo de la educación. En la dimensión curricular, específicamente, la emergencia de la interculturalidad y el bilingüismo vernáculo en la escuela ha llevado a que profesores, direc- 
tivos y autoridades políticas reconozcan su limitada o inexistente preparación para desarrollar esta nueva concepción educativa, generándose, con ello, los espacios y las condiciones para el ingreso de actores comunitarios $^{10}$ a las aulas y para la inclusión de saberes mapuche-williche en el currículum escolar. Dicha inclusión se perfila como una de las transformaciones sociales y culturales más relevantes para la escuela, al propiciar una nueva forma de participación de los pueblos indígenas en el ámbito de la educación. La participación de cultores, kimches (cf. Nota 10), autoridades mapuche y líderes comunitarios en el contexto del proceso educativo, los ha legitimado no sin conflictos- como interlocutores válidos para el diseño e implementación de una nueva forma de concebir y construir el currículum escolar.

Entran así en escena, a través del nuevo curriculum, expresiones fragmentarias de la matriz cultural ${ }^{11}$ mapuche-williche, proceso en el cual los saberes y conocimientos indígenas son objeto de intensos conflictos de legitimidad que ponen en tensión las relaciones de poder construidas en el trayecto histórico de la escuela en la sociedad mapuche-williche. Estas inclusiones, de manera heterogénea, van activando procesos de resistencia epistémica que traspasan en múltiples direcciones y ámbitos los muros físicos y simbólicos del sub-sistema escolar. En esta línea de reflexión, me interesa formular algunas hipótesis relativas a los impactos re-etnizadores no previstos en las lógicas de la política pública en educación intercultural y a los modos en que esos impactos transforman la EIB en un campo ${ }^{12}$ de resistencia político-epistémica.

En esta perspectiva, exploraré en un primer apartado el debate conceptual y empírico de las experiencias educativas interculturales. Examinaré, específicamente, el concepto de interculturalidad y su relación con los procesos educativos, y exploraré a su vez las relaciones teóricas entre poder, curriculum e interculturalidad. En un segundo apartado, abordaré la relación entre las resistencias epistémicas y los procesos re-etnizadores. Expondré para ello las dinámicas de la EIB en la Región de Los Lagos, las tensiones identitarias y las apuestas descolonizadoras implicadas en los proyectos educativos interculturales y las posibilidades de repensar la EIB a partir de los propios procesos de resistencias que en ella se incuban. Finalmente, en un tercer apartado, expondré a modo de conclusiones algunas consideraciones sobre las dinámicas político-etnizadoras generadas en relación a la EIB.

\section{Educación intercultural: aproximaciones teóricas y empíricas}

La característica común de conceptos como "interculturalidad”, “educación”, “currículum”, “re-etnización”, “resistencias epistémicas”, “descolonización”, entre otros, es su polisemia, la que está signada, principalmente, por el posicionamiento ideológico, teórico e interpretativo que se tiene respecto del contexto socio-histórico del que somos parte como ciudadanos. Intentaré dar aquí algunas precisiones conceptuales al respecto. 


\section{El concepto de interculturalidad en cuestión}

La materialización política y jurídica de la interculturalidad, oscila entre la asimilación-integración, el reconocimiento de la diversidad cultural y propuestas que buscan reformular el Estado nacional en un Estado plurinacional. En esta orientación, Muñoz Sedano (2001: 87-89), citando a Bartolomé (1997), señala la existencia de tres concepciones ideológicas que proponen diversas orientaciones para atender los fenómenos relativos a la inclusión de los grupos culturalmente diversos y a los modos en que se regulan las relaciones entre estos grupos:

a) Concepciones orientadas a la afirmación hegemónica de la cultura del país de acogida. En estas concepciones se proponen lógicas asimilacionistas, compensatorias y segregacionistas.

b) Concepciones orientadas al reconocimiento de la pluralidad de culturas en aspectos globales o parciales dentro del Estado-nación. En esta concepción se proponen lógicas multiculturales y de pluralismo cultural.

c) Concepciones orientadas hacia una sociedad intercultural basada en la simetría cultural. En estas últimas se contemplan políticas de reconocimiento de derechos a la diferencia hasta la refundación de los Estados-nación.

Con una orientación similar, Walsh (2010: 78) plantea que las diversas perspectivas de la interculturalidad se pueden agrupar en tres concepciones matriciales: la relacional, la funcional y la crítica.

a) La interculturalidad relacional en la que se reconoce la existencia, el contacto y el intercambio entre dos o más culturas; relaciones que se pueden dar en condiciones de simetría o desigualdad. Esta lógica, según Walsh, tiende a invisibilizar el conflicto, la dominación y la colonialidad que se sustenta en relaciones de poder subordinantes.

b) La interculturalidad funcional en la que se plantean metas de inclusión de la diversidad y diferencia en la perspectiva de promover el diálogo, la tolerancia y la convivencia. Las lógicas que sustentan esta concepción no ponen en tensión las reglas del juego, por lo que es compatible con la lógica del modelo "neo-liberal”. Walsh (Ibid.: 78) señala que en ella se reconoce "[...] la nueva lógica multicultural del capitalismo global”.

c) La interculturalidad crítica que no radica en el abordaje de la diversidad o diferencia como problema sino en las lógicas y estructura del sistema-mundo moderno / colonial / racial; es decir en el "[...] reconocimiento de que la diferencia se construye dentro de una estructura y matriz colonial de poder racializado y jerarquizado, con los blancos y "blanqueados” en la cima y los pueblos indígenas 
y afrodescendientes en los peldaños inferiores” (Ibid.: 78).

Como lo menciona la autora, desde la posición crítica, “[...] la interculturalidad se entiende como una herramienta, como un proceso y proyecto que se construye desde la gente $-y$ como demanda de la subalternidad-, en contraste a la funcional, que se ejerce desde arriba" (Ibid.: 78). Los debates sobre interculturalidad en América Latina se mueven en este eje de tensión, aunque quizás con algunos grados de diferencial semántico. Pues, vemos el contraste existente entre las lógicas neoliberales que influyen en los proyectos globales de desarrollo y las perspectivas de desarrollo, resistencia y descolonización expresadas por los pueblos indígenas y afrodescendientes.

La lógica multicultural del capitalismo global impregna los proyectos de desarrollo de los Estados-nación. Derruyttere (2001) y Acuña (2003) exponen que tanto las sociedades occidentales como las que se encuentran bajo sus influencias están atrapadas en un escenario de interconexión en el que les es difícil la interlocución, siendo objetos de un flujo unidireccional hegemónico en relación a los usos y beneficios que esta produce. Ello no solo genera impactos en las formas en que se organizan los procesos productivos, sino que también operan dispositivos de selección para incluir y excluir. Acuña (2003), citando a CEPAL, manifiesta que esta interconexión globalizadora es un proceso controvertido, pues si bien ha implicado

“[...] la integración más estrecha de los países y los pueblos del mundo, producto de la reducción de los costos de transporte y comunicación y el desmantelamiento de las barreras artificiales a los flujos de bienes, servicios, capital y conocimiento (CEPAL) para la gran mayoría de los países en vías de desarrollo se convirtió en su karma reflejado en el incremento de su pobreza (Acuña 2003: 218).

En el caso de Chile, las políticas sociales y económico-productivas están signadas por la perspectiva neoliberal, generándose así nuevos marcos institucionales y normativos en los sistemas de salud, seguridad social, de producción, tributación, educación, entre otros. Nuevas regulaciones y desregulaciones afectan cotidianamente a las personas que quedan al margen de los beneficios de la "modernidad: desarrollo y progreso". En el caso de los pueblos indígenas, las lógicas económicas de la globalización penetran en sus territorios donde asumen el control de los recursos y la transformación de los ecosistemas: reemplazo de la biodiversidad nativa por especies exóticas, desaparición de las fuentes de aguas, violación de los espacios sagrados; con ello, privación de derechos. Para Deruyttere (2001: 1), “[...] los pueblos indígenas no sólo enfrentan grandes riesgos de una pérdida acelerada de su sociedad y cultura, sino también grandes potencialidades de articulación con identidad de su sociedad y cultura a la economía global”.

Al suscribir el Estado chileno los lineamientos de la "lógica multicultural del capitalismo global (Wash Ibíd. 78) las políticas 
implementadas en el campo de la interculturalidad se manifiestan en términos dicotómicos, subyaciendo posicionamientos que oscilan entre concepciones relacional y funcional. Estos es, frente al movimiento político indígena, las acciones del Estado se centran en la penalización de la protesta, mientras en materias como educación, salud y ordenamiento territorial, sus discursos se movilizan entre la denegación de derechos, el reconocimiento del contacto y el llamado al diálogo. Por otra parte, los reclamos de los pueblos indígenas por mayor autonomía e inclusión de la interculturalidad en los distintos ámbitos de la acción estatal forman parte de las luchas de resistencias y oposición a las lógicas de desarrollo que materializan los gobiernos. En este sentido, suscribo el planteamiento de que las propuestas de interculturalidad en Chile

\begin{abstract}
“[remiten] a una praxis que tiene por objeto contrarrestar la opresión política a la vez que permite imaginar la post-colonialidad. Es definida y operacionalizada en los márgenes del Estado por unos agentes sociales subalternos que buscan acabar con el proceso de invisibilización cultural al que fueron y siguen siendo sometidos. Pertenece al ámbito de las luchas y reivindicaciones sociales en contra de un Estado que no ha cesado de imponer una representación de la nación chilena como criolla y de una patria sin indios” (Boccara 2012: 15).
\end{abstract}

Mis experiencias en comunidades mapuche-williche me llevan a sostener que un importante segmento de líderes, autoridades, dirigentes y docentes indígenas elaboran discursos políticos y educativos que se distancian de los subyacentes predominantes en la política pública indígena. Su concepción del Estado se plasma de este modo en el transitar desde un concepto de Estado universal a uno pluriversal. En esta lógica, la propuesta de interculturalidad devela otra epistemología, más bien alejada de la globalización neoliberal, y “[...] ligada a geopolíticas de lugar y espacio, desde la histórica y actual resistencia de los indígenas y de los afrodescendientes, hasta sus construcciones de un proyecto social, cultural, político, ético y epistémico orientado a la descolonización y a la transformación” (Walsh 2007: 47).

Los procesos de re-etnización son materializaciones políticas expresadas a través de discursos y prácticas orientadas a construir dinámicas de adhesión cultural y de autoafirmación identitaria ancladas en la construcción de subjetividades y sentidos articulados en saberes, conocimientos, prácticas y lógicas de relación que definen los componentes históricos, lingüísticos y culturales de determinados grupos. Al imbricarse con prácticas de descolonización, estos procesos se traducen en el abandono de significados y sentidos construidos en escenarios y contextos históricos y espaciales ajenos. El cuestionamiento ético y político a las relaciones de poder y la búsqueda de estrategias que permitan desarticular las estructuras en que se fundamentan las condiciones de subordinación es lo que, en mi opinión, dan cuerpo a procesos de descolonización. 


\section{Escuela e interculturalidad}

Giroux (1992: 94) señala que los centros escolares son “[espacios] culturales marcados por relaciones complejas de dominación y resistencia” en los cuales las lógicas predominantes en el discurso político oficial tienden a construir relatos que, a través de diversas estrategias de operación ideológica, cosifican la cuestión educativa. Este modo de naturalizar la cultura, sus prácticas y sus dimensiones simbólicas, despolitiza la construcción curricular a la vez que desprovee los contenidos de los modos y de la condición socio-histórica de su producción.

Por el contrario, las experiencias de educación intercultural, pese a las condiciones racistas y de exclusión que persisten en las dinámicas escolares, restituyen por una parte a la escuela y a sus procesos su naturaleza política y, por otra, a sus actores la conciencia de ser sujetos políticos, y por tanto su facultad de concebir diferentes posibilidades de intervención en su entorno inmediato. De este modo, sin ser su objetivo, la EIB configura una gama de posibilidades de agenciamiento por parte de los sujetos indígenas para construir, utilizar y gestionar un proyecto político colectivo distinto al que lleva adelante el Estado. En este sentido, la EIB evidencia la posibilidad de politizar las relaciones sociales y los modos de distribución del poder entre el Estado, los pueblos indígenas y los demás grupos que conforman el entramado nacional.

El desarrollo de la interculturalidad en la escuela permite, por lo menos, tensionar las inscripciones y adscripciones ideológicas en todos los rangos de la sociedad y cultura dominante. Posibilita comprender que el eje de tensión ideológica que vertebra la producción, la interpretación y la efectividad de los significados culturales, se mueve entre la reproducción mecánica y el cuestionamiento que sitúa el espacio escolar. De este modo, la construcción del curriculum intercultural configura un nuevo campo de confrontación política.

Compartiendo los planteamientos de Giroux (1992), las ideologías que circulan, se negocian y confrontan en la escuela intercultural constituyen los referentes desde los cuales los actores del proceso producen, interpretan y otorgan efectividad a los significados que comparten para dar forma a los procesos pedagógicos. Pero, además, las experiencias educativas interculturales, al activar la conciencia de la naturaleza política del quehacer de la escuela, permiten poner en valor el constructo socio-histórico y cultural de la sociedad mapuche-williche, no solo como fuente para el currículum, sino como dispositivo de diferenciación que nutre un proyecto socio-político propio sustentado en el principio de autodeterminación.

En síntesis, la emergencia de la EIB -entre otros ámbitos ${ }^{13}$ - pone de algún modo a la escuela y a los dispositivos de los diferentes sistemas del Estado a reflexionar sobre el dilema de su pecado original: la toma de conciencia de los actos del pasado orientados a la asimilación y las acciones de hoy tendientes a contribuir en las dinámicas de (re-)construcción, y en el 
fortalecimiento del proceso de creación de lo que en un pasado cercano excluyó.

\section{Poder, curriculum e interculturalidad}

La concepción e implementación de la EIB implica la intervención en diferentes niveles y dimensiones del campo de la educación; el curriculum es uno de ellos. En este ámbito de intervención, el currículo es de relevancia toda vez que sus consecuencias en la construcción de las subjetividades individuales y colectivas imprimen adscripciones a matrices ideológicas y valóricas, a imaginarios y representaciones sociales, a sentidos de justicia y legitimación de prácticas de poder, a epistemes y modos de producción de conocimiento, a concepciones de persona y valor de la vida, de respeto a la naturaleza, la biodiversidad y a conceptos de desarrollo. En este sentido, es necesario tener en cuenta que el curriculum

[...] expresa determinados valores e intereses, opciones políticas e ideológicas presentes en la sociedad, así como determinadas concepciones epistemológicas y pedagógicas que orientan tanto la selección de los contenidos, como los principios y medios a través de los cuales esos contenidos van a ser enseñados. En tal sentido, todo diseño curricular dejará plasmado, explícita o implícitamente, el sustento teórico, político e ideológico que posee y, sus opciones se sustentarán en las concepciones que se tengan acerca de la sociedad que se quiere construir, de la forma en que se concibe la producción del conocimiento, de la información cultural que se cree vale la pena o no seleccionar para convertirla en contenidos de estudio, así como también la forma en que se concibe la "transmisión" del mismo por medio del acto educativo (Sánchez 2001: 1).

Sobre este ámbito de intervención, las tensiones políticas e ideológicas son intensas, toda vez que, según cómo se conceptualice, su despliegue tiene efectos diferentes. Al respecto, Cox (2001: 214) expone que

[...] el curriculum corresponde a los planes y programas de estudio, o el conjunto de contenidos, en un sentido amplio, que, organizados en una secuencia, el sistema escolar se compromete a comunicar. Al mismo tiempo, el currículum es una selección cultural con propósitos formativos, que organiza la trayectoria de alumnos y alumnas en el tiempo y que, en los contenidos, esquemas mentales, habilidades y valores que contribuye a comunicar, es un regulador de la experiencia futura.

El curriculum, como dispositivo, forma parte de un sistema político estratégico a través del cual se asegura la reproducción ideológica y simbólica de los grupos de poder (Fuenzalida 2012). En él se expresa una "red de relaciones" que articula los sentidos y las significaciones de quienes participan en su elaboración. La concepción de un curriculum que orienta las 
lecturas de las experiencias interculturales devela la naturaleza políticoideológica de la educación intercultural y la perspectiva de quienes participan en su construcción. De esta manera, esta conceptualización da cuenta de los desplazamientos ideológicos de las re-semantizaciones significativas propuestas por las políticas educativas y por los discursos provenientes desde el movimiento político indígena.

El impacto de estas re-significaciones y de los cambios de sentidos de las conceptualizaciones que los grupos en tensión elaboran en torno a la EIB no es mensurable en el corto plazo. La reificación de los contenidos, del constructo socio-histórico y de las prácticas culturales, se produce en el marco de la racionalidad curricular predominante en las propuestas y experiencias educativas interculturales generadas desde las esferas de poder del Estado. La cosificación implica que estas experiencias sean concebidas como simples proyectos o espacios curriculares orientados a asegurar los aprendizajes de los y las estudiantes establecidos en el curriculum prescrito. Con ello se configura un currículum des-historizado que responde a los intereses del Estado y no a las necesidades de los pueblos indígenas.

Las transformaciones semánticas que evidencian los desplazamientos ideológicos emergen en contextos que Estados nación como Chile consideran relevantes y coherentes con los procesos de modernización de sus sistemas educativos. Ejemplo importante de aquello es el constructo descentralización ${ }^{14}$, con el que se "[...] pretende que la escolarización se haga más responsable de las exigencias de la política; se trata de crear un mecanismo más eficaz para poner en práctica las órdenes determinadas por el Estado” (Popkewitz 2000: 182).

En esta línea, Alvarez-Santullano et al. (2008), citando a Corazza (1997), sostienen que la concepción curricular predominante está basada en las tradiciones cartesiana y positivista que subyacen en el pensamiento occidental moderno, cuyos efectos sociales y subjetivos derivados asumen un carácter supuestamente neutro, a-histórico, normativo y universal, del cual quedan excluidas las relaciones de poder-saber, los antagonismos y las dominaciones. En esta perspectiva, se entiende como posible que, en las escuelas, las orientaciones curriculares interculturales puedan estar siendo intervenidas por los agentes educativos que no comparten la racionalidad predominante o hegemónica, asumiendo que el curriculum es un concepto que posee una "[...] naturaleza política que se expresa como una propuesta educativa a través de la que se operacionalizan las concepciones ideológicas sobre las personas, la sociedad, la cultura y el modelo de desarrollo, por tanto, [como toda propuesta política] queda sujeto a cuestionamiento, revisión y negociación” (Fuenzalida 2011: 64).

En el marco de las relaciones escuela-comunidad generadas en torno a las experiencias pedagógicas interculturales, y pese a los controles institucionales, han emergido iniciativas que problematizan las 
relaciones de poder generadas entre la sociedad mapuche, el Estado y la sociedad chilena. Algunas de ellas las podremos ubicar en una perspectiva crítica a las lógicas del Estado en tanto expresan discursos y prácticas de resistencias que fracturan la tradición de "neutralidad" de la escuela.

\section{Re-etnización y curriculum intercultural en la Región de Los Lagos: conflictos y resistencias epistémicas en proceso}

La instalación de la EIB en la Región de Los Lagos tensiona los modos en que mapuche-williche y chilenos conceptualizan la escuela, sus procesos y los dispositivos de control que inciden fuertemente en la configuración de las subjetividades individuales y colectivas. La concepción de una escuela orientada a la dominación también puede ser un espacio de resistencia y descolonización. En este apartado, revisaré, entre otros, los modos en que la EIB se ha desarrollado en la región, que posiblemente no se distancia de la implementación en otras regiones del país. Exploraré además su incidencia en la configuración de las identidades y desarrollaré algunas reflexiones en torno a las resistencias epistémicas que se presentan en el curriculum como posibilidad de repensarla. En esta reflexión utilizaré algunos textos contenidos en entrevistas a profesores comprometidos con la EIB, las que han sido obtenidas en mi experiencia de investigación que he desarrollado durante 10 años $^{15} \mathrm{y}$, los últimos dos años, en el proyecto "Dispositivos curriculares: apropiación y descolonización performativa de la educación intercultural en áreas mapuches (Fondecyt $\left.N^{\circ} 1121024\right) ”$.

\section{La EIB en la Región de Los Lagos}

En sus dos décadas de experimentación en la inclusión de las lenguas indígenas en las bases curriculares, la EIB ha presentado impulsos y retrocesos en tres momentos clave. El primero corresponde a su irrupción en la escuela rural, y con ello la inclusión de los modos de vida indígena en el curriculum escolar. El sustrato jurídico que ampara estas posibilidades educativas son la Ley Indígena, la Convención Internacional de los Derechos del Niño y el Decreto Supremo $\mathrm{N}^{\circ} 40$ de 1996 que faculta a los equipos docentes a readecuar la secuencia de los objetivos fundamentales y los contenidos mínimos obligatorios de acuerdo a los requerimientos de sus proyectos de "experimentación curricular". En la fase inicial, de experimentación, los docentes destacan la libertad para fijar planes y programas de estudios $^{16}$. En el ejercicio de esta garantía, los establecimientos deben respetar los objetivos y contenidos mínimos obligatorios establecidos por los decretos[17] No 40 de 1996 y N²20 de 2008 y los complementarios que cada uno de ellos fije.

$\mathrm{Al}$ respecto, uno de los docentes entrevistados señala: 
“el hecho que puedas hacer tus propios planes y programas, tu propio PEI, tu proyecto de centro educativo, te dan todas las facilidades para que tu armes tu propio curriculum, que puede incluir objetivos complementarios, que puedes diseñar un curriculum EIB, se puede hacer, está permitido” (Profesor 1).

Por otra parte, las prescripciones establecidas se traducen en preguntas como ¿qué es la educación intercultural? y ¿cómo se construye?, ¿cómo resolver los problemas de formación que no permiten abordarla? Como respuestas a estas preguntas, docentes y actores indígenas desarrollan dispositivos curriculares y didácticos que se orientan a la construcción de un cuerpo de contenidos culturalmente pertinentes para el curriculum intercultural bilingüe. Las estrategias del profesorado se fundan principalmente en la construcción de un registro de saberes de las comunidades a través de tareas de investigación realizadas por estudiantes en sus propios hogares. Diccionarios, inventarios toponímicos y antroponímicos, relaciones de contenidos con algunas prácticas culturales, rescate de lengua, medicina tradicional, entre otros, constituyen el reservorio de saberes que se curricularizarán. Además, la implementación de la EIB tensiona ideológicamente la escuela y la comunidad; en ambos espacios las posiciones no son homogéneas. Los conceptos predominantes en el discurso pedagógico son: rescate, valoración, mediación, mejoramiento de la autoestima, aprendizajes, entre otros.

El segundo momento en la historia de la EIB en la Región de Los Lagos se manifestó con la implementación del Programa Orígenes y con una voz más protagónica del MINEDUC, a través de programas de formación y perfeccionamiento docente en EIB, el incremento del número de escuelas, el apoyo brindado en la elaboración de sus Proyectos Educativos Institucionales (PEI), subsidios para contratar a educadores tradicionales, financiamiento para adquirir materiales e implementar proyectos de investigación. El incremento en el número de escuelas vuelve a activar las preguntas originales, pero ya se vislumbra en el discurso de los actores implicados con la interculturalidad nuevas interrogantes orientadas a explorar posibilidades políticas de la acción pedagógica y curricular. Así también, se aprecia cierto distanciamiento en las conceptualizaciones que generan el Estado y los actores con implicación política. En torno a ello, los conceptos que entran en juego por parte del Estado aluden a los propósitos del proyecto de desarrollo, el aseguramiento de la calidad como foco de la acción pedagógica, eficiencia y efectividad en el uso de los recursos, incremento en los indicadores de los resultados obtenidos en pruebas estandarizadas, multiculturalismo e inclusión de la diversidad. Por parte de docentes y líderes políticos mapuche-williche, los conceptos constitutivos de sus discursos corresponden al fortalecimiento de la identidad, la autonomía, políticas de revitalización lingüística y autodeterminación, entre otros.

Al respecto, algunos docentes señalan que la interculturalidad posibilita una educación más pertinente en tanto recoge los recursos culturales de las comunidades, para incorporarlos en una enseñanza contextualizada. 
Esta condición hace posible que los niños se constituyan en protagonistas de sus procesos de enseñanza aprendizaje. Como parte de estos constructos, los docentes señalan:

“es la educación que realmente debiéramos hacer nosotros o lo que debieran aprender nuestros niños, no estoy haciendo discriminación entre unos y otros, el tipo de educación que debieran tener los niños partiendo del contexto sociocultural donde viven, es decir que sean ellos digamos, que sean ellos los involucrados en el proceso, que sean ellos que construyan su propio aprendizaje, pero partiendo de donde están ya, respetando sus aprendizajes previos, su cultura su idiosincrasia, sus costumbres y tradiciones, para mí eso es en grandes rasgos la EIB” (Profesor 2).

“La EIB es para mí un enfoque educativo que está destinado a ser una educación pertinente en áreas donde conviven distintos grupos étnicos, grupos de distinta procedencia cultural” (Profesor 1).

Desde la perspectiva de los docentes, en esta etapa de su desarrollo, la EIB cumple con la propiedad de fomentar los procesos de autoafirmación étnica o identitaria y fortalecer el sentido de pertenencia cultural. Este fortalecimiento identitario se construye a partir del mejoramiento de la autoestima de los [¿niños o profesores?] indígenas que superan la situación de subvaloración a la que están sujetos por las manifestaciones de discriminación de la que suelen ser objetos. La autovaloración implica el asumir un estado de conciencia de ser diferentes en tanto son miembros de un grupo cultural distinto. Por otra parte, este estado de conciencia les permite construir relaciones con otros grupos en un plano de igualdad -pese a las manifestaciones de discriminación que sufren-, las que se constituyen en manifestaciones de respeto con las culturas que interactúan:

“creo que los mayores logros están por el área [que] fomenta la identidad, el sentido de pertenencia a la comunidad, el sentirse indígena, el hecho de sentirse de darle un valor que han tenido siempre, pero que está desconocido por el resto de la sociedad e incluso ha habido una discriminación abierta hacia los apellidos indígenas, me ha pasado a mí, les ha pasado a todos los que hemos estudiado alguna vez en la universidad y después vamos demostrando que tenemos condiciones para estar en los lugares que nos han sido vetado, prohibido en otros tiempos” (Profesor 1).

El tercer momento de la EIB en la Región de Los Lagos corresponde a la inclusión del principio de interculturalidad en la Ley General de Educación -Ley N²0370 de 2009-y la dictación de normas para implementar el sector de Lengua Indígena en las escuelas -Decreto de Educación N²80 de 2009- y la determinación de la carga horaria de la enseñanza de lengua indígena en las bases curriculares -Decreto N²960 de 2012. Se aprecia entonces un mayor distanciamiento ideológico entre el Estado y los docentes y líderes indígenas comprometidos con las propuestas de la 
interculturalidad crítica, además de una mayor producción de evidencias y diversidad teóricas. El pluralismo ideológico se amplia y complejiza. Sin embargo, la política pública educativa en interculturalidad parece enfrentarse a retrocesos significativos, pues el Estado introduce nuevos marcos regulatorios y la potenciación de un bilingüismo globalizante que hace presión sobre las escuelas que implementan experiencias educativas interculturales propias. Dicha política, a su vez, simplifica y descomplejiza la interculturalidad en términos teóricos, toda vez que a partir de la Ley N²0370 de 2009, el Estado entiende interculturalidad en educación como reconocimiento y valoración del estudiante indígena en tanto individuo portador de una especificidad cultural originaria, considerando su lengua, cosmovisión e historia (cf. Artículo $3^{\circ}$, Letra l).

Los conceptos que signan los discursos del Estado son: bases curriculares, calidad de la educación, sector de aprendizaje de lengua indígena, inclusión, diversidad, globalización, entre otros. Por su parte, los docentes y líderes que suscriben miradas emancipadoras se ubican en un plano opuesto, y hablan más bien en términos de educación mapuche, proyecto político, autodeterminación y educación descolonizadora. Esta perspectiva se puede apreciar en los planteamientos de algunos docentes entrevistados, para quienes las acciones de la escuela se han constituido en un eficiente vehículo de disolución de los sistemas identitarios de los alumnos/as indígenas, deslegitimando el valor social y epistemológico de las lenguas vernáculas:

“[en] el proceso de pérdida la escuela ha cumplido el papel de ignorar el conocimiento de origen de los alumnos. En este caso la escuela es culpable, se podría decir por omisión de la cultura, más encima, en muchos casos de negación, de opacamiento, de negación... cuando la política del establecimiento apunta a un desarrollo académico [basado en] un modelo occidental se hace más difícil todavía...” (Profesor 5).

"primero que nada, la escuela para los mapuches todavía sigue siendo un espacio no mapuche, es un espacio winka" (Profesor 6).

"los alumnos de educación de adultos son alumnos que han desertado del sistema escolar, y bueno [...], es un problema que tiene que ver con el sistema social en realidad y con el sistema educacional. Obviamente que lo discrimina y que le coarta su libertad individual y entonces ya el alumno ve, el alumno mapuche cree principalmente que es un lastre ir a la escuela, porque se le castra en cierta manera su identidad, entonces obviamente deserta. Los alumnos de educación de adulto son alumnos que tienen 18 años, que están haciendo primero y segundo medio y otros cabros [entiéndase jóvenes] que están haciendo tercero y cuarto ya, ellos han repetido varios años que se han quedado fuera del sistema” (Profesor 8). 
"En [escuelas] de sectores rurales donde hay un alto componente indígena y donde existe un mayor porcentaje de hablantes, entonces en ese tipo de alumnos se produce la mayor castración, resulta que sin la EIB históricamente se ha prohibido la lengua, que se hable en mapudungun por el castellano, también históricamente yo conversaba con un hermano acá en San Juan de la Costa, el es de mi generación, 20 o 25 años, el decía que cuando iban a la escuela a pies pelados, no le dejaban jugar a la chueca, no podían hablar su lengua” (Profesor 8).

\section{EIB y tensiones identitarias en torno a los procesos descolonizadores}

La construcción de la EIB ha develado múltiples tensiones, entre ellas, las tensiones identitarias. A la vez que promueve ciertas adscripciones, establece los puentes para construir una etnicidad en relación con la otredad. Tal como exige precisar los elementos que configuran sus rasgos diferenciadores, vincula a las personas y a sus grupos con el mundo que se encuentra más allá de las difusas fronteras étnicas. Esta doble entrada lleva a la EIB a tensionar la construcción colonial de la identidad indígena, de su fijación estática en un momento del pasado a su construcción política y dinámica. La historización de la identidad supone admitir "el nacimiento de un nuevo tipo de memoria histórica formulada con arreglo a la nueva coyuntura [...] de carácter modernizador"18. Esta tensión se materializa en las formas en que se conceptualiza su estar en el mundo -posición, rol e identidad.

En la tensión generada por "[...] la necesidad de ser universal y, simultáneamente, la necesidad de ser local” (Boissier 2005: 48), sin poner en riesgo lo que Anderson (1993) denomina la "comunidad imaginada”, el sujeto mapuche-williche se moviliza en un eje de tensión signado por dinámicas re-etnizadoras y de asimilación/integración. Estas dialécticas otorgan sentido vital a la "nación mapuche imaginada" donde la comunidad -ámbito reduccional-, lo rural, lo urbano, el cyber-espacio y la localidad son lugares que, de manera dialéctica, fortalecen las posibilidades de construcción del proyecto de continuidad política e histórica de la sociedad/nación mapuche.

La conciencia de pertenencia a un pueblo, según Bertho e Iriarte (2003) supone la conciencia de un origen -la reducción marginada- y destino común -la nación imaginada. Si esta conciencia, a su vez, se genera en condiciones de subordinación respecto de una sociedad dominante, la identidad étnica asume el papel de brújula que posiciona al grupo y a sus miembros en mapas cognoscitivos -u horizontes- colectivamente construidos. Desde mi perspectiva, la construcción identitaria mapuche-williche, más allá de la transformación de las formas de vida, producto de las dinámicas ya descritas, está implicando procesos de continuidad y transformaciones de los modos en que se construye lo que los identifica y diferencia. Lo 
mapuche-williche construido por personas asumidas como sujetos, se traduce en "luchas que cuestionan su status de individuo [en relación con el poder, en otros aspectos] sostienen el derecho a ser reconocidos como diferentes” (Foucault 1988: 6). Esto es, personas implicadas políticamente en los procesos histórico-sociales de su construcción individual y colectiva, en la producción de relaciones y la construcción de sentidos que los sitúan como sujetos históricos, toda vez que son "[capaces] de ubicar el conocimiento que [construyen] en tanto parte de sus opciones de vida y sociedad" (Zemelman 2010:18). El sujeto mapuche-williche, pese a los discursos que lo reducen a una expresión local, como sujeto histórico, “es a la vez un constructor de la historia y un agente de transformación en la historia”19, su historia.

La identidad, como proceso en construcción (Gros 1999), es marcada por los modos en que los sujetos, tanto individuales como colectivos, subjetivan sus propias historicidades. En el caso de la sociedad mapuchewilliche, la toma en cuenta de sus transformaciones y diferencias internas es indudablemente marcada por el conflicto, las negociaciones y las interacciones interculturales e interétnicas con la sociedad dominante. La usurpación de sus territorios y recursos, la marginalidad y la segregación, la integración y la escolarización, la modernización y la diáspora ${ }^{20}$, configuran escenarios que, para los mapuche-williche, han implicado, por una parte, un proceso de desplazamiento y dispersión forzada desde su lugar de origen -lof o machulla ${ }^{21}$ - hacia mundos urbanos, multiculturales y cosmopolitas y, por otra, re-elaboraciones identitarias que mestizan o hibridan la definición de lo mapuche.

Estas dinámicas han llevado a la sociedad mapuche-williche a enfrentar fuertes tensiones internas para definir lo propiamente mapuchewilliche y, por consiguiente, para evaluar los modos de abordar su relación con el Estado y la sociedad chilena, luchar por el territorio y construir un proyecto político de continuidad histórica. En estas pugnas, se observa un abanico de posiciones yendo desde definiciones esencialistas planteadas en la perspectiva de una matriz cultural históricamente fijada que delimita unívocamente lo que es y lo que no es mapuche-williche, hasta lecturas que, desde una matriz cultural en movimiento, consideran el dinamismo cultural y las influencias mutuas con otros grupos en la construcción de identidades móviles, histórica y socialmente situadas. Se expresan así definiciones polares: ser comprometido con la resistencia mapuche o ser awincado $^{22}$, lo que implica un vínculo distinto con el mundo occidental.

Junto con lo anterior, es importante destacar también la existencia de un creciente contingente de intelectuales, empresarios, profesionales y técnicos mapuche que construyen sus vínculos familiares, amicales, laborales, educativos, en la ciudad, en el campo y entre estos dos espacios, incidiendo fuertemente en la construcción identitaria y en la trama de sentidos ideológicos, epistémicos y políticos que sostiene la tensión mencionada. La relación entre la sociedad mapuche-williche y dominante se adapta, creando nuevas formas de interactuar de manera intra e intercultural. Estas diná- 
micas tensionan los modos de identificarse como mapuche-williche; se reconfiguran y se crean nuevas fronteras a partir de la confrontación, del diálogo, de la negociación, del intercambio, de la resistencia y de la asimilación.

\section{Resistencias epistémicas: posibilidades para re-pensar la EIB}

Las dinámicas de resistencia y articulación que se construyen en torno a la educación intercultural y a los procesos políticos con el Estado abren nuevas posibilidades para abordar las relaciones interculturales. Estas posibilidades enriquecen los discursos que articulan políticamente reivindicaciones y propuestas de desarrollo y control territorial ancladas en procesos educativos interculturales. Esta plataforma revela, a mi modo de ver:

a) la construcción de un proyecto educativo autónomo propio, orientado a dar continuidad política y cultural a la sociedad mapuchewilliche;

b) la emergencia de procesos político-culturales que enfatizan la desincretización -o des-catolización- de los elementos esenciales de la intimidad mapuche-williche, por ejemplo, el nguillatún ${ }^{23}$;

c) la interpelación política que realizan líderes y autoridades mapuche williche a la EIB con el propósito de crear las condiciones de simetría apropiadas para el conocimiento propio en las instancias de diálogo y negociación durante las prácticas de curricularización -una orientación a la mapuchización y morenización ${ }^{24}$ del curriculum intercultural-; y

d) la articulación de procesos culturales y socio-políticos de resistencia mapuche conducidos por jóvenes que, en diversas modalidades y tiempos, han vivido experiencias de EIB.

Las concepciones que orientan el desarrollo de las experiencias de EIB se han complejizado gradualmente, siguiendo un patrón de densificación ideológica presente en los discursos, actuaciones y materializaciones educativas que favorecen la re-etnización, activan prácticas de resistencia y promueven lógicas de descolonización. Lo cual implica concebir el currículum como un sistema estratégico en el que se puede poner en tensión las lógicas de poder. Pero también el currículum constituye un entramado por el que pueden ingresar significaciones ideológicas y construcciones culturales para asegurar su legitimación epistemológica.

La representación de la vida social como objeto escolarizado es producto de un proceso de decisión política que, articulado a otros contenidos, estructura una propuesta curricular. La representación de este objeto 
escolarizado, en un contexto de relación interétnica o de zona de contacto ${ }^{25}$, al ser curricularizado desde una concepción tradicional, lo conflictúa, naturaliza y traviste ontológica y epistemológicamente. Las consecuencias de ello son la fragmentación y el divorcio de los contextos de producción y reproducción social donde se genera la red de sentidos que constituye la urdimbre vital de la comunidad.

Esta disociación activa, en el curriculum intercultural, tensiones epistémicas en la concepción y desarrollo de las representaciones de los procesos de producción y reproducción de saberes indígenas y locales, transformando la escuela en un campo de disputa político-simbólica que visibiliza y confronta las construcciones conceptuales e ideológicas subyacentes en y sobre los saberes construidos y reproducidos en los márgenes del establishment escolar.

La interacción significativa de saberes contiene una alta carga ideológica, configurando con ello, desde la militancia mapuche-williche, rupturas epistémicas, toda vez que constituyen expresiones de resistencia simbólica que buscan de-construir los imaginarios monoculturales asentados en la base del sistema educativo nacional. Así, estas rupturas e insurgencias epistemológicas emergen "[...] envuelt[a]s en los reclamos de aprecio y conservación de saberes y de filosofías indígenas en muchos ámbitos” (Marcos 2010: 1).

Por otra parte, estos procesos están instalando una relación de interacción recíproca puesto que este renovado aprecio está incidiendo fuertemente en la relación entre escuela y comunidad. Por un lado, es posible señalar que, epistémicamente, la EIB está morenizando la escuela y los procesos de enseñanza-aprendizaje y, por otro lado, desde la escuela se refuerza el proceso de valorización y revitalización de los saberes mapuche, que vertebran dos procesos: el de re-etnización y el de resistencia epistémica. Todo ello posibilita lo que Marcos ha conceptualizado como la emergencia, con renovado ímpetu, de aquellos saberes ocultos que han estado largamente escondidos, invisibilizados, extintos, disueltos, prohibidos y desaparecidos. Es decir "[la] reaparición de tradiciones, cosmologías y de cosmovisiones" ${ }^{26}$.

\section{Algunas consideraciones de cierre}

Al posibilitar la participación de actores sociopolíticos y culturales diversos, la construcción de la EIB ha visibilizado la trama de tensiones y conflictos que la sitúan como un campo de disputa simbólica que no sólo ha develado las dinámicas micropolíticas de la relación entre la escuela y las comunidades inmediatas - urbanas y rurales- sino que, además, ha activado procesos re-etnizadores que movilizan sectores de la sociedad mapuche en la construcción de un proyecto político propio. En estos procesos de reetnización, se advierten prácticas de interacción política que promueven, por una parte, procesos orientados a otorgar legitimidad político-simbólica 
y epistémica del constructo socio-histórico y cultural y, por otra, nuevas formas de crear y re-crear las relaciones interculturales. Estas "nuevas formas" de relacionarse interculturalmente se plasman en discursos que articulan políticamente reivindicaciones y propuestas de desarrollo, tensionando los modos de construir lo mapuche.

El desarrollo de la EIB está incidiendo así en el desplazamiento de las expectativas que se tienen de la escuela y de los sentidos del currículum escolar. El eje saber-poder gira en dirección de la sociedad mapuche-williche que, a través de sus liderazgos, comienza a construir una posición de fortaleza con respecto a los requerimientos e influencias ideológicas de la escuela, filtrando los contenidos suministrados, y marcando los énfasis y las intencionalidades políticas y culturales del currículum de la EIB. En algunos casos, la magnitud de esta posición es tal que la tensión entre la comunidad y la escuela se torna en una situación conflictiva explícita y/o subyacente. Como he señalado en párrafos anteriores, las experiencias educativas interculturales son interpeladas por los intereses y las necesidades de construcción de procesos de autoafirmación étnica que posibiliten, por un lado, el fortalecimiento identitario y el reconocimiento de la historia propia, y por otro, la diferenciación cultural y la catalización de fenómenos de resiliencia colectiva (Fuenzalida y Casas 2010).

En síntesis, las tensiones, los conflictos, la escolarización y los desplazamientos forzados y voluntarios pueden ser entendidos como un proceso dialéctico que está provocando continuidades, rupturas y reelaboraciones identitarias, territoriales, simbólicas y epistémicas. Esta realidad, al margen del dolor que provoca, está generando nuevas posibilidades de construcción de un proyecto político de continuidad histórica y epistémica de la sociedad mapuche. 


\section{Notas}

${ }^{1}$ Este artículo es producto de la reflexión desarrollada en el marco del proyecto de investigación FONDECYT N¹121024: "Dispositivos curriculares: apropiación y descolonización performativa de la educación intercultural en áreas mapuches”, CONICYT/ FONDECYT, Concurso regular 2012. Agradezco a Blanca Fernández y a Bastien Sepúlveda por sus lecturas, comentarios, observaciones y sugerencias realizadas en las distintas fases de la construcción de este texto.

${ }^{2}$ En relación a esta afirmación, sugiero revisar el D.F.L. N5291 de 1930, también conocido como Ley de Instrucción Primaria que fija las normas que regularon la educación pública hasta la Reforma de 1968, cuyas orientaciones en materia indígena siguen el mismo derrotero: el silencio. En términos de experiencia práctica, sugiero revisar el texto de Canales (1998).

${ }^{3}$ La Ley $\mathrm{N}^{\circ} 19.253$ de 1993, conocida en Chile como Ley Indígena, en su Artículo 32, mandata a la Corporación Nacional de Desarrollo Indígena (CONADI) para que, "en coordinación con los organismos que correspondan", desarrolle un sistema de educación intercultural bilingüe en zonas "de alta densidad indígena", con el objetivo que los niños y niñas indígenas puedan "desenvolverse en forma adecuada" en las dos culturas, la local, de origen "indígena”, y la chilena presentada como "la global”. Consultar en: http://www.leychile.cl/Navegar?idNorma=30620\&buscar=Ley+19253

\footnotetext{
${ }^{4}$ Respecto a esta categoría, me refiero a proyectos educativos interculturales que se implementan en las escuelas en el espacio y tiempo curricular denominado "horas de libre disposición”. Estas iniciativas suelen ser desarrolladas como talleres de jornada escolar completa, como asignaturas denominadas planes y programas propios, inserciones curriculares, entre otros. Para el desarrollo de estas iniciativas, las escuelas compiten entre sí en base a propuestas presentadas en fondos concursables de proyectos, tanto del Ministerio de Educación como de la CONADI.
}

${ }^{5}$ Decreto Supremo de Educación $\mathrm{N}^{\circ} 280$ del Ministerio de Educación Pública, publicado en Diario Oficial el 25/09/2009. Consultar en: http://www.leychile.cl/ Navegar?idNorma=1006477\&buscar=Decreto+supremo+de+educaci\%C3\%B3n+n\%C2\%B0+280

${ }^{6}$ Estas experiencias fueron implementadas en distintas comunas de la antigua Provincia de Valdivia -hoy Región de Los Ríos- y de las provincias de Osorno y Chiloé. Actualmente, algunos de estos jardines se han cerrado, sin embargo su cobertura se ha ampliado hacia sectores urbanos, tanto en jardines de administración directa de la JUNJI como a través del mecanismo de administración delegada a los municipios. Además, la Fundación Integra ha iniciado experiencias similares en sus jardines ubicados en distintas comunas de la región.

${ }^{7}$ Los mapuche-williche constituyen uno de los grupos o identidades territoriales del entramado socio-político mapuche. El concepto williche se utiliza para identificar a las personas mapuche del sur, aquellos que habitan la Fütawillimapu -las grandes tierras del sur- que corresponde a las actuales regiones de Los Ríos y de Los Lagos. Este territorio es uno de los cuatro grandes Fütalmapu -grandes tierras- en los que se organizó, según lo expone la memoria histórica, el territorio mapuche histórico.

${ }^{8}$ En 1995, la CONADI convocó las escuelas rurales emplazadas en comunidades a un 
concurso de presentación de proyectos de EIB. En esa oportunidad, se financiaron las propuestas de las escuelas Laupulli y Trosco, ambas en la comuna de San Juan de la Costa, Provincia de Osorno. Por su parte, el Ministerio de Educación financió en 1996 tres experiencias en la antigua Provincia de Valdivia -hoy región de Los Ríos-, en las escuelas de Ngongahue y Coihueco en la comuna de Panguipulli, e Isla Huapi en Futrono.

${ }^{9}$ En el año 2000, la política indígena de carácter compensatorio se canalizó a través del Programa Orígenes, impulsado por el gobierno “[...] como elemento central de la política orientada a mejorar de manera integral las condiciones de vida y promover el desarrollo con identidad de las comunidades de los pueblos aymara, lican antai y mapuche en el área rural” (MINEDUC 2009: 9).

${ }^{10}$ Me refiero con ello al proceso mediante el cual se materializó la educación intercultural en territorio mapuche. Los actores comunitarios que cumplen funciones pedagógicas en el aula son especialistas de conocimiento mapuche, ya sea en salud, lengua, epistemología, artesanía, historia, organización, etc. A estos especialistas, se les denomina genéricamente kimches -personas sabias-, o más específicamente ülmen, lonko, lawentuchefe, weupife, niempin, entre otros; mientras que en el sistema escolar, se les conoce como educadores tradicionales.

${ }^{11}$ Siguiendo a Caniuqueo (2011: 75), la matriz cultural se puede entender como "[...] la configuración de estructuras en periodos históricos determinados, en la cual se establecen cambios y continuidades. Dichos cambios además se realizan en espacios locales, lo cual indica que las normas apuntan al mantenimiento de esa diversidad, más que a una homogenización y una hegemonía”.

${ }^{12}$ Desde una perspectiva Bourdiana, entiendo el concepto de campo como aquel espacio en que los actores sociales se encuentran política y epistemológicamente implicados, en el que se generan vinculaciones conflictuadas, articuladas y /o negociadas entre personas y grupos relacionados. Para mayor profundización véase Bourdieu, Pierre (2002), Campo de poder, campo intelectual, itinerario de un concepto, Editorial Montressor, Buenos Aires.

${ }^{13} \mathrm{Al}$ señalar "entre otros ámbitos”, considero las experiencias de salud intercultural, los procesos productivos, la gestión territorial y el patrimonio natural, el fortalecimiento organizacional, las dinámicas de los conflictos políticos, las prácticas de espiritualidad y la movilización de la memoria.

${ }^{14}$ Otros conceptos que cumplen esta misma función en educación son calidad, equidad, pertinencia, igualdad de oportunidades, entre otros.

${ }^{15}$ Entre otras experiencias de investigación he participado en los proyectos "Discursos y Prácticas de las educadoras de Párvulos en los Jardines Infantiles Étnicos en la Región de Los Lagos: Estrategias para la Implementación de la Educación Intercultural” ( $N^{\circ}$ 0304). Investigación bi-anual años 2004-2005. Dirección de Investigación. Universidad de Los Lagos. Osorno. Proyecto folio 45755 “Cosmovisión, prácticas sociales, ceremonias y ritualidad Mapuche Williche en la Región de Los Lagos”. Consejo de la Cultura y de las Artes. Línea de Promoción y Conservación del Patrimonio Inmaterial. Fondart-Universidad de Los Lagos. Proyecto "El Discurso Indígena sobre la Educación Intercultural Bilingüe: Un Estudio de las Representaciones Sociales de Líde- 
res Indígenas de la Región de Los Lagos ( $\mathrm{N}^{\circ}$ 002706) Investigación bi-anual años 2006-2007. Dirección de Investigación. Universidad de Los Lagos. Osorno y Proyecto de investigación Fondecyt № 1080420 "La inserción de saberes en el curriculum de la Interculturalidad como ruptura y continuidad con el espacio social mapuche Huilliche”.

${ }^{16}$ Ley $\mathrm{N}^{\mathrm{0}}$ 18.962, Ley orgánica Constitucional de Enseñanza ya derogada y sustituida por el DFL $\mathrm{N}^{\circ} 2$ de 2010, Artículo $18^{\circ}$.

${ }^{17}$ Los decretos señalados son aquellos que contemplan los objetivos y contenidos mínimos obligatorios y los objetivos transversales fundamentales. El Decreto $\mathrm{N}^{\circ} 40$ está orientado a la Enseñanza General Básica y el Decreto Nº 220 a la Educación Media.

${ }^{18}$ Extracto de la nota "El problema de lo urbano y lo rural”, publicada por Marcos Valdés (2000), en línea: http://www.mapunet.org/documentos/mapuches/urb_rur.htm

${ }^{19}$ Extracto de la nota "La problemática del sujeto histórico", publicada por Manuel Rodríguez (2006), en línea: http://paradygmes.unblog.fr/2006/07/24/la-problematicadel-sujeto-historico/

${ }^{20}$ La diáspora es un proceso demográfico relevante en la construcción histórica mapuche. Los desplazamientos a que remite el uso de este concepto tienen impactos políticos, culturales y económicos profundos que redefinen constantemente las dinámicas propias de la sociedad mapuche. Para mayor profundidad sobre este fenómeno, sugiero revisar los textos de Ancan y Calfío (1999) y Millaleo (2011). Para aproximarse al debate sobre el concepto de "diáspora”, sugiero revisar el texto de Fernández (2008).

${ }^{21}$ Concepto que dice relación con el territorio y la comunidad de origen.

${ }^{22}$ Se denomina awincado a una persona mapuche que suscribe prácticas sociales, culturales y/o posiciones político-ideológicas cercanas a las de la sociedad chilena. Este concepto es una derivación castellanizada del concepto wingka que en las comunidades de la región se utiliza para referirse a la persona no mapuche.

${ }^{23}$ El ngillatún es el ritual de mayor relevancia espiritual en la cultura mapuche. Dependiendo de las condiciones de su realización, esta ceremonia puede tener el carácter de rogativa o ser una manifestación de agradecimiento por los dones otorgados; dependiendo del territorio, puede presentar diferencias en su puesta en escena. Estas ceremonias fueron colonizadas con inclusión de iconografía cristiana católica, símbolos que paulatinamente están siendo excluidos de la ritualidad mapuche; los precursores de estos procesos, no sin resistencias y apoyos de los más ancianos, son jóvenes y profesores que se relacionan con la educación intercultural y las luchas políticas de la sociedad mapuche-williche.

${ }^{24}$ Con el concepto de morenización del curriculum intercultural y de la escuela estoy refiriéndome al otro-piel, asociado a la persona indígena para aludir a la influencia de la racionalidad que subyace en el episteme subalternizado (saberes, conocimientos, practicas y ritualidad) que tensiona, conflictúa, interpela y reconstruye las lógicas del curriculum escolar, de las dinámicas micropolíticas y a los cambios en la relación entre escuela y comunidad con la participación de agentes locales -educadores tradicionalesen la formación de los estudiantes.

Comprendo el riesgo de alguna interpretación racializada que implica el uso del 
constructo morenización. Con esta categoría no intento avalar o promover estas perspectivas teóricas e ideológicas, sino por el contrario, mi propósito es exponer en situación de conflicto el racismo epistémico subyacente en la racionalidad curricular predominante, a la vez, dar cuenta de algunas de las tensiones generadas por la interacción entre los epistemes moderno- occidental-colonial-escolar y el mapuche williche en los procesos de construcción e implementación del curriculum intercultural. Respecto del concepto racismo epistémico, consúltese a Grosfoguel, Ramón (2011), "Racismo epistémico, islamofobia epistémica y ciencias sociales coloniales", en Tabula Rasa, $N^{\circ} 14$, Universidad Colegio Mayor de Cundinamarca, Colombia, pp. 341-355. Consultar en: http://www.redalyc.org/articulo.oa?id=39622094015

${ }^{25}$ Por "zonas de contacto" se entienden aquellos lugares en que confluyen o entran en comunicación culturas que han seguido históricamente trayectorias separadas y establecen una sociedad, con frecuencia en el contexto de una relación colonial (Pratt 1996:3).

${ }^{26}$ Extracto de la nota "La insurgencia de saberes avasallados" publicada por Sylvia Marcos (2010), en línea: http://cuadernosfem.blogspot.com/2010/01/la-insurgenciade-saberes-avasallados.html 


\section{Bibliografía}

Acuña, Fabián (2003), “El malestar en la globalización”, en Innovar. Revista de Ciencias Administrativas y Sociales, Universidad Nacional de Colombia, Vol. 13, $\mathrm{N}^{\circ}$ 21, pp. 217-222.

Alvarez-Santullano, Pilar, Amílcar Forno, Rita Rivera y Pedro Fuenzalida (2008), La inserción de saberes en el curriculum de la interculturalidad como ruptura y continuidad con el espacio social mapuche huilliche: contexto del problema, Proyecto FONDECYT N¹080420, CONICYT, Universidad de Los Lagos.

Ancan, José y Calfío, Margarita (1999), "Retorno al país mapuche. Reflexiones sobre una utopía por construir”, en Liwen, N5 , Centro de Estudios y Documentación Mapuche Liwen, Temuco, pp. 43-77.

Anderson, Benedict (1993), Comunidades imaginadas: reflexiones sobre el origen y la difusión del nacionalismo, Fondo de Cultura Económica, México DF.

Bertho, Marcelo e Iriarte, Rodrigo (2003), “Ser mapuche en un contexto pos reduccional. Las mil caras de la etnicidad”, en Cyber Humanitatis, ${ }^{\circ}$ 27, Universidad de Chile, en línea: http://web.uchile.cl/vignette/ cyberhumanitatis/CDA/texto_simple2/0,1255,SCID\%253D7521 \%2526ISID\%253D347,00.html

Boccara, Guillaume (2012), “La interculturalidad como campo social”, en Cuadernos Interculturales, Vol. 10, N¹8, Universidad de Valparaíso, pp. 11-30.

Boissier, Sergio (2005), “¿Hay espacio para el desarrollo local en la globalización?”, en Revista de la CEPAL, N86, CEPAL, Santiago de Chile, pp. 47-62.

Bourdieu, Pierre (2002), Campo de poder, campo intelectual, itinerario de un concepto. Editorial Montressor, Buenos Aires, Argentina

Canales, Pedro (1998), "Peyepeyen, Escuelas Chilenas en contextos mapuche: integración y resistencia (1860-1950)”, en Última Década, N9, CIDP, Viña del Mar, pp. 1-15.

Caniuqueo, Sergio (2011), "Reflexiones sobre el uso de la cultura como matriz cultural en el caso Mapuche. Algunas notas introductorias de principios del siglo XX”, en Cuadernos Interculturales, $N^{\circ} 17$ (año 9), Universidad de Valparaíso, Valparaíso, pp. 73-97.

Cox, Cristián (2001), “El Curriculum Escolar del Futuro”, en Revista Perspectivas en Política, Economía y Gestión, Vol. 4, N², Universidad de Chile, Santiago de Chile, pp. 213-232. 
Deruyttere, Anne (2001), Pueblos indígenas, globalización y desarrollo con identidad. Algunas reflexiones de estrategias, Unidad de Pueblos Indígenas y Desarrollo Comunitario, Departamento de Desarrollo Sostenible, Banco Interamericano de Desarrollo, en línea: www.bvsde.paho.org/bvsacd/ cd27/puin2.pdf?

Fernández, Mireya (2008), “Diáspora: la complejidad de un término” en Revista Venezolana de Análisis de Coyuntura, Instituto de Investigaciones económicas y sociales, Caracas. Vol. 14, N², pp. 305-326.

Foucault, Michel (1988), “El sujeto y el poder”, en Revista Mexicana de Sociología, Universidad Nacional Autónoma de México, Vol. 50, №3, pp. 30-30.

Fuenzalida, Pedro y Mariela Casas (2010), “La educación Intercultural Bilingüe como campo de tensión política entre el mundo Mapuche-Williche y el Estado”, en Líder, Vol. 16, Universidad de Los Lagos, Osorno, pp. 73-84.

Fuenzalida, Pedro (2011), “Tensiones político-epistémicas de la representación y reproducción social indígena en el curriculum intercultural”, en Loncón, E. y Hecht A. C. (comp.), Educación Intercultural Bilingüe en América Latina y el Caribe: balances, desafíos y perspectivas, Equitas, Santiago de Chile, pp. 60-69.

Idem (2012), Escuela y pueblo mapuche williche: tensiones político-ideológicas en torno a la legitimidad del episteme mapuche en el curriculum de la interculturalidad de la Fütawillimapu, ponencia presentada en el V Congreso Internacional de Lenguas y Literaturas Indoamericanas y XV Jornadas de Lengua y Literatura Mapuche, Temuco, 14, 15 y 16 de noviembre de 2012.

Giroux, Henry (1992), Teoría de la Resistencia en Educación, una pedagogía para la oposición, Siglo XXI Editores, México DF.

Gros, Christian (1999), “Ser diferente por (para) ser moderno, o las paradojas de la identidad. Algunas reflexiones sobre la construcción de una nueva frontera étnica en América Latina”, en Análisis Político, N³6, Instituto de Estudios Políticos y Relaciones Internacionales (IEPRI), Universidad Nacional de Colombia, pp. 3-20.

Grosfoguel, Ramón (2011), “Racismo epistémico, islamofobia epistémica y ciencias sociales coloniales”, en Tabula Rasa, N 14, Universidad Colegio Mayor de Cundinamarca, Colombia, pp. 341-355.

Millaleo, Salvador (2011), “La recreación de la identidad étnica en la protesta mapuche: un punto de partida para el uso de la teoría de sistemas sociales en la política de la identidad”, en Revista de Antropología, N²3, Universidad de Chile, pp. 51-79.

MINEDUC (2009), Sistematización de los distintos ámbitos de interven- 
ción en los establecimientos educacionales del Programa Orígenes, Programa de Educación Intercultural Bilingüe, Ministerio de Educación, Gobierno de Chile, Santiago.

Muñoz, Antonio (2001), Enfoques y modelos de Educación multicultural e intercultural, Universidad Complutense de Madrid, en línea: http:// www.aulaintercultural.org/IMG/pdf/sedano.pdf

Pratt, Mary Luis (1996), Apocalipsis en los Andes: zonas de contacto y lucha por el poder interpretativo, Centro Cultural del BID, Washington DC.

Popkewitz, Thomas (2000), Sociología política de las reformas educativas, Ediciones Morata, Madrid.

Sánchez, Miguel (2001), Diseño Curricular y Educación Intercultural Bilingüe, ponencia presentada al Congreso Internacional de Universidad Católica, en línea: http://www.redeib.org/modules/Downloads/ articulos_documentos/Curriculum_y_educación_intercultura.pdf

Walsh, Catherine (2007), "Interculturalidad y colonialidad del poder. Un pensamiento y posicionamiento "otro" desde la diferencia colonial”, en Castro-Gómez, Santiago y Grosfoguel, Ramón (comp.), El giro decolonial: reflexiones para una diversidad epistémica más allá del capitalismo global, Siglo del Hombre Editores, Universidad Central y Pontificia Universidad Javeriana, Bogotá.

Idem (2010), “Interculturalidad crítica y educación intercultural”, en Jorge Viaña, Luis Tapia y Catherine Walsh (comp.), Construyendo Interculturalidad Crítica, Instituto Internacional de Integración del Convenio Andrés Bello, La Paz.

Zemelman, Hugo (2010), Aspectos básicos en la propuesta de la conciencia histórica o del presente potencia, IPECAL, México DF. 